\title{
The Research of Brand Loyalty on the Perspective of Customer Value
}

\author{
Yanan He \\ Department of Business Administration \\ Fuzhou University of International Studies and Trade \\ Fuzhou, China \\ E-mail: 1329538603@qq.com
}

\author{
Yan Yan \\ Department of Teaching Development Center \\ Fuzhou University of International Studies and Trade \\ Fuzhou, China \\ E-mail: 2024301275@qq.com
}

\begin{abstract}
It is difficult to get advantage if the companies only stay in the product and quality level. Brand marketing era is already here, and competition between brands has gradually become the focus.How to make customers brand loyalty and how enterprises can establish and strengthen the loyalty relationship between brand and customers, have become the focus of many businesses. This research is studying the brand loyalty from the perspective of customer value. Based on the research design, we proposed hypotheses and finally found the research results: efficiency value, economic value, service value and emotional value influence brand loyalty at the same time, the emotional value has biggest influence, and service value variables are relatively unremarkable. Finally, some reasonable suggestions are given for the future branding construction, and we also want to have a contribution on reference value for the further study, maintenance and promotion of brand loyalty.
\end{abstract}

\section{Keywords-brand loyalty; customer value; Apple Corporation}

\section{INTRODUCTION}

For today's world economic development trend, the market competition is not just a simple price competition, quality competition and service competition. It is difficult to get advantage if the companies only stay in the product and quality level. Brand marketing era is already here, and competition between brands has gradually become the focus. 'Forbes', as a business magazine with a high profile in the United States, rewarded 'The world's most valuable brands' each year since 2010. Every year the release of the list attracts a wide range of attention and debate. It can be seen that more and more entrepreneurs and investors realize that the brand is the most valuable property of the enterprise and the brand loyalty is the most valuable customers of the enterprise. On the other hand, the market structure changes, the market for electronic technology products is overwhelmingly in the buyer's market. Information on products and brands is complex and diverse. In the context of internationalization, it has become easier for brands to enter the market. Consumer choice space increases and factors that affect consumer decision-making are also increasing. In terms of products, the product homogenization is serious and the substitution is strong. The development of functional attributes and marketing strategies for the products of other companies are becoming more and more similar with Apple. How to make customers brand loyalty and how enterprises can establish and strengthen the loyalty relationship between brand and customers, have become the focus of Apple and many businesses.

\section{LITERATURE REVIEW}

\section{A. Customer Value Dimension}

In the study of customer value, many scholars have proposed the basis of the division of customer value dimension, one of the most representative is Sheth (2000) five-dimensional model and emotional value. According to the five angles to analyze the customer value, Sweeney and others on this basis, further subdivided the function value into quality and price factors. Demonstrates the quality from the function-quality and functional value-price, emotional value, social value four dimensions to meet the scientific nature of the customer value.

By combing the literature, and draw lessons from Sweeney's four dimensions of customer value's research model, combined with the case of apple, and the characteristics of electronic science and technology industry to make some adjustments: think the price can not fully reflect the consumer purchase decision, including factors such as sales promotion, so this paper will be the price value to the economic value, and electronics industry after-sales service is very important, so add a service value, social value is included in the sentimental value. Therefore, it is concluded that the customer value dimension of this paper is divided into effect value, service value, economic value, emotional value, these four aspects.

\section{B. Customer Value Dimension}

Integrated the theory review of customer value and brand loyalty, brand loyalty measurement index system of this paper is based on customer value, combined with the degree of customer value words divided thinking: emotional value, efficiency value, service value, economic value, combined with the company and the characteristics of the products of science and technology industry, to choose the appropriate indicators for each dimension measurement. Customer value indicators include the following:

- Functions value: mainly consider the physical attributes of the product, this paper studies this kind of case is apple products of science and technology enterprises, so in order to consumers for the product 
quality, function, technical skills, convenience attribute perceived value as a concrete measure.

- Economic value: it is the customer perception of the purchase price and other cost, purchase cost that is paid with product price corresponding cash costs, other costs such as learning to use cost and maintenance cost, cost, etc., promotional activities will also affect economic value perception.

- Service value: to read and provide after-sale help to the businessman is consumer awareness, to aftersales service and service quality as a measure.

- Emotional value: it is the consumer perceived by buying products on the value of the emotional, to form the height of the spirit of the brand identity, this paper with the brand culture and brand image to reflect consumers' attitude to life, personality cultivation and other spiritual symbol.

- Because of brand loyalty cannot direct measurement, in the above theory study shows the brand loyalty is a combination of behavior and attitude, so this study with heavy buying behavior, oral behavior, as well as purchase commitment to measure three aspects.

Because brand loyalty cannot direct measurement, in the above theory study shows the brand loyalty is a combination of behavior and attitude, so this study with heavy buying behavior, oral behavior, as well as purchase commitment to measure three aspects.

From what has been discussed above, we can build brand loyalty based on customer value perspective study of evaluation index system, as shown in figure:

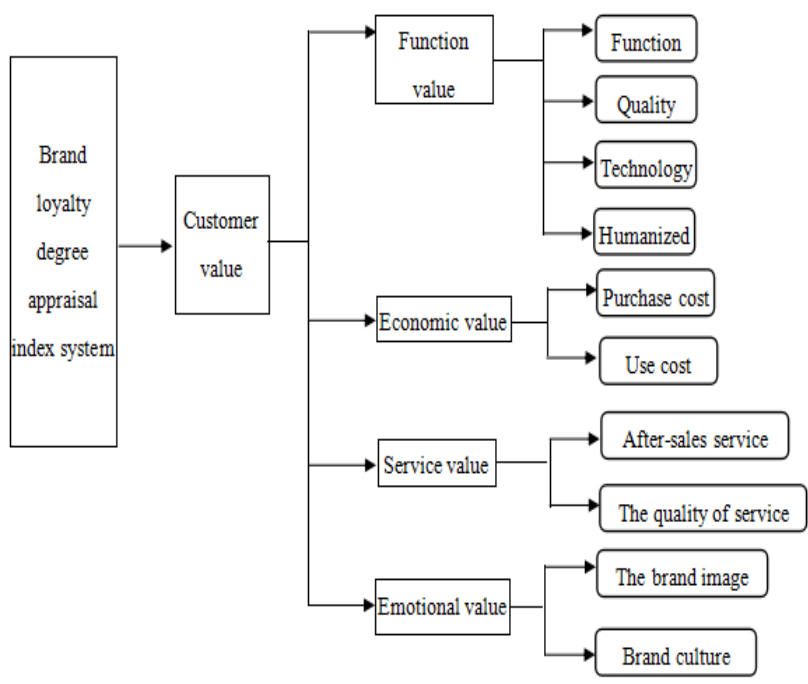

Figure 1. The evaluation indicator system of this research.

\section{RESEARCH DESIGN}

\section{A. Questionnaire Design}

The questionnaire of this research is based on the abovementioned assessment indicator system. From four dimension of customer value which is emotional value, efficiency value, service value and economic value under the perspective of brand loyalty, with quantitative indicators clearly show the results of the study, and put forward suggestions for enterprises to improve brand loyalty.

The respondents of this research are people who have bought or used the Apple products. The answers of questionnaire will be designed to utilize five-point Likert Scale. Each scale will have five options. Use this scale to indicate the unity or disapproval of the statement of forgiveness. Questionnaires include three parts:

- Basic description. Have you bought or used any Apple product?

- Personal information. Including sex, age, profession and monthly income.

- Variables questionnaire. Including the score of the variables statement.

\section{B. Research Method}

After questionnaire recycling, input, collate, calculate and analyze relevant data. Using SPSS to perform validity, reliability and multiple regression analysis. Through this to make sure about its consistent and effective, at the end using multiple regression analysis, the relationship between the variables has been shown. The result of this research will be come out.

\section{RESEARCH ANALYSIS}

\section{A. Descriptive Result of Questionnaire}

This study was used to obtain data from questionnaires. The total questionnaires are 350 , and recovery of valid questionnaires is 293 . The effective rate is $81.42 \%$. The basic information of the questionnaire includes: sex, age, education background, occupation and monthly salary.

TABLE I. DATA SUMMARY

\begin{tabular}{|c|c|c|c|}
\hline Item & Category & Sample & Percentage \\
\hline \multirow[t]{2}{*}{ Sex } & Male & 133 & $45.4 \%$ \\
\hline & Female & 160 & $54.6 \%$ \\
\hline \multirow[t]{5}{*}{ Age } & Under 18 & 27 & $9 \%$ \\
\hline & $18-31$ & 130 & $44 \%$ \\
\hline & $31-40$ & 77 & $26 \%$ \\
\hline & $41-50$ & 45 & $15 \%$ \\
\hline & Above 50 & 14 & $5 \%$ \\
\hline \multirow[t]{7}{*}{ Occupation } & Student & 47 & $16.04 \%$ \\
\hline & Public Institution & 52 & $17.75 \%$ \\
\hline & Professional Technology & 41 & $13.99 \%$ \\
\hline & Private Entrepreneurs & 30 & $10.24 \%$ \\
\hline & $\begin{array}{l}\text { Industrial and } \\
\text { Commercial Service }\end{array}$ & 72 & $24.57 \%$ \\
\hline & Freelancer & 18 & $6.14 \%$ \\
\hline & Others & 33 & $11.26 \%$ \\
\hline \multirow{6}{*}{$\begin{array}{l}\text { Monthly } \\
\text { income } \\
\text { (CNY ¥) }\end{array}$} & 1000 and under & 29 & $10 \%$ \\
\hline & $1001-3000$ & 81 & $28 \%$ \\
\hline & $3001-5000$ & 78 & $27 \%$ \\
\hline & 5001-7000 above & 55 & $19 \%$ \\
\hline & 7001-9000 above & 32 & $11 \%$ \\
\hline & 9000 above & 18 & $6 \%$ \\
\hline
\end{tabular}




\section{B. Reliability of Questionnaire and Validity Analysis}

Generally speaking Cronbach's Alpha Coefficient over 0.6 means the reliability can be accepted. Through table 2, all the variates and whole Cronbach's Alpha Coefficient values are more than 0.7. Thus, the reliability of this questionnaire is higher. All the gained data has higher reliability, result of this research is reliable.

This study used factor analysis to test the structural validity of questionnaires. First the questionnaire data was tested by $\mathrm{KMO}$ and Bartlett, KMO greater than 0.8 is suitable for factor analysis. However, the statistical significance of Bartlett sphericity test is less or equal to the significant level which can be used for factor analysis. The results are seen in form table 2 . The KMO is 0.839 , greater than 0.7. The Bartlett statistical value is significantly different from 0 . The data is suitable for factor analysis.

TABLE II. RELIABILITY AND VALIDITY TEST

\begin{tabular}{|c|c|c|}
\hline \multicolumn{3}{|c|}{ Reliability statistics } \\
\hline Programme & Cronbach's Alpha & $\begin{array}{c}\text { Number of } \\
\text { items }\end{array}$ \\
\hline Efficiency value & 0.821 & 4 \\
\hline Economic value & 0.704 & 3 \\
\hline Service value & 0.792 & 3 \\
\hline Emotional value & 0.833 & 4 \\
\hline Brand loyalty & 0.722 & 18 \\
\hline Total & 0.778 & 0.839 \\
\hline Kaiser-Meyer-Olkin & \multicolumn{2}{|c|}{2356.175} \\
\hline Chi-square & \multicolumn{2}{|c|}{0} \\
\hline Df & \multicolumn{2}{|c|}{} \\
\hline Sig. & \multicolumn{2}{|c|}{} \\
\hline
\end{tabular}

\section{Correlation and Multiple Regression Analysis}

Before regression analysis, a correlation test was needed to prove that there was a correlation between variables. The correlation coefficient can reflect the correlation between variables. When the correlation coefficient passed, the significance testing during 0.05 or 0.01 , there is a significant correlation. Conversely, it can be rejected. There is no correlation between variables. The results showed in the form 3-3, according to the result. Emotional value, efficiency value, service value and economic value have significant correlation with brand loyalty.

In correlation analysis, there is certain correlation among these four dimensions and brand loyalty. The relationship between variables is not completely determined by correlation analysis, so regression analysis is required. Regression analysis experiment results in the causal relationship between multiple independent variables and dependent variable. In the research of this paper, the emotional value, efficiency value, service value and economic value are the independent variable, and brand loyalty is the verification of the specific relationship of the dependent variable.

From form table 3 regression analysis statistics show, the Sig. of emotional value, efficiency value and economic value is lower than 0.05 which means these values have significant positive influence in brand loyalty. But when service value greater than 0.05 which is non-significant. When these four variables came at the same time, there is no proof that service value variables can affect brand loyalty, so it is not included in the following standardized regression equation. Thus, according to the measured regression coefficient, this regression equation can be made which is:

Brand Loyalty $=0.108 *$ Efficiency Value + $0.422 *$ Economic Value $+0.321 *$ Emotional Value

TABLE III. DATA SUMMARY

\begin{tabular}{|c|c|c|c|c|c|}
\hline \multicolumn{7}{|c|}{ COEFFICIENT(a) } \\
\hline & B & $\begin{array}{c}\text { Standard } \\
\text { Error }\end{array}$ & & $\mathrm{t}$ & Sig. \\
\hline Constant & 2.121 & 1.079 & & 1.989 & 0.045 \\
\hline Efficiency & 0.108 & 0.048 & 0.099 & 1.938 & 0.048 \\
\hline Economic & 0.422 & 0.062 & 0.265 & 4.9 & 0 \\
\hline Service & 0.137 & 0.071 & 0.089 & 1.793 & 0.065 \\
\hline Emotional & 0.321 & 0.048 & 0.402 & 8.006 & 0 \\
\hline \multicolumn{7}{|c|}{ Dependent Variable: Loyalty } \\
\hline
\end{tabular}

Obviously, the emotional value has the highest influence. The brand image of Apple has always been impressive and well admitted by public. This could be the key element to consumer's brand loyalty.

Based on the results of correlation statistics are known as emotional value, efficiency value, service value and economic value these four-independent variables influence the brand loyalty in a positive way. The highest is economic value and emotional value, second would be service value, the lowest one is efficiency value. As technology and electronic products become more and more similar, the decision to buy depends on consumers' purchasing power and emotional preferences, so it is why the emotional value has the highest influence, and the efficiency has the lowest influence for brand loyalty to Apple.

However, from the regression statistics result, efficiency value, economic value, service value and emotional value influence brand loyalty at the same time, the emotional value has biggest influence, and service value variables are relatively unremarkable. Therefore, after this study, the following conclusions are deduced: When service value affects brand loyalty separately, it especially affects the effect. However, for the whole enterprise, these four independent variables produced at the same time, according to the normalized regression equation, if a brand wanted to improve brand loyalty efficiently, they could put improving emotional value and economic value in a vital position, then efficiency value.

\section{SUGGESTIONS}

\section{A. Improve the Functional Properties of The Products}

Quality is the basic measurement of the products, for electronic industry they need more to continuously strengthen product quality. As for Apple, the improvement of its hardware, keeping the originality as the biggest 
advantage and also focusing on training the professional technician are the three key point of complete the function of the products.

\section{B. Optimize Pricing Strategy}

Use a reasonable price to suit the target customers. It does not mean that the price should be as low as possible. The key is to find the acceptance of price range from different customer range. Then make a price strategy. The value improvement can be achieved by using promotions and other price-off strategies. On the one hand, it can attract more new customers. On the other hand, it has improved the economic value and great promoting effect of cultivates and maintains brand loyalty.

\section{Build the Brand Integrated Service System}

For building the integrated service system to increase the competitive edge, Apple needs the improvement of pre-sales, sales and after-sales service. For pre-sales, the professional skill consult of Apple device can be provided at this time. During the sales time, payment suggestions, details of customers' needs can be provided by sales stuff. At aftersales time, their main purpose is to fix the problems that came from customers. Value their complaint, enlarge the complain channel. All above these can improve the brand loyalty.

\section{Enhance the Brand's Emotional Content}

Maintain a good corporate image. Corporate image is the most direct influence factor of brand image; Apple has two ways to improve their corporate image from both inside and outside. The social image building is the main idea of outside corporate image building, Apple can organize some charity activities, social program ect. By building from inside is improving employees' quality, because the evaluation from customers is directly influenced by employees' activities.

The Apple spirit is technology, environment protection, artificial, humanity and creativity. Nowadays, there are many similar products on the market, Apple needs to emphasize their differences, emphasize the Apple device can be imitated, not be overcame. Using the multi-media to express the Apple culture, understand the popular emotional values for being more specific in conveying the brand idea.

\section{REFERENCES}

[1] Woodruff, R. Customer Value: the next source for competitive advantage, Journal of the Academy of Marketing Science, 1997, (25), pp. 139-153.

[2] N. Sheth, I. Gross Consumption Values and Market Choices. New York:McGraw-Hill, 1997, pp.123-141.

[3] Sweeney, J. C. Consumer Perceived Value: the development of a multiple item scale. Journal of Retailing, 2001, (77), pp. 203-220.

[4] Sun Lihui, Li Shengxiao. Brand Management. Beijing: Higher Education Press, 2015. pp.245-267

[5] Li Yuanyuan. The Impact of Customer Perceived Value on Brand Loyalty of Mobile Phone Users. Jilin: Jilin University, 2013.

[6] Ye Yilin, Shao Yiming. Research on Brand Loyalty Based on Customer Value. Jiangsu: Nanjing University of Science and Technology, 2005.

[7] Huang Haitao. Customer Value - Oriented Brand Equity Model and Empirical Analysis. Finance research, 2009, (1), pp.125-132.

[8] Philip Kotler. Principles of Marketing. Beijing: Tsinghua University Press English, 2002. pp.345-349. 